\title{
A Biomechanical Method for Reconstruction of Tumbling Trampoline- Associated Cervical Spine Injuries Using Human and Anthropometric Test Dummy Data
}

\author{
Desmoulin $\mathrm{GT}^{1^{\star}}$, Marc Rabinoff ${ }^{2}$, Brad Stolz ${ }^{3}$ and Michael Gilbert ${ }^{4}$ \\ ${ }^{1}$ GTD Engineering, 218 E 4th Avenue, Vancouver, BC, (Canada), V5T 1G5, Canada \\ ${ }^{2}$ Rabinoff Consulting Services, 7600 West Coal Mine Ave., Unit A, Littleton, USA \\ ${ }^{3}$ Pie Consulting and Engineering, 12441 W. 49th Avenue, Unit 8, Wheat Ridge, CO 80033, USA \\ ${ }^{4}$ Gilbert Engineering, 12441 W. 49th Avenue, Unit 8, Wheat Ridge, CO 80033, USA \\ "Corresponding author: Geoffrey Thor Desmoulin, GTD Engineering, 218 E 4th Avenue, Vancouver, BC, (Canada), V5T 1G5, Canada, Tel: \\ 303-819-9891/303-819-9891; E-mail: gtdesmoulin@gtdengineering.com
}

Received date: Feb 20, 2014; Accepted date: Mar 18, 2014; Published date: Mar 25, 2014

Copyright: (c) 2014 Desmoulin GT, et al. This is an open-access article distributed under the terms of the Creative Commons Attribution License, which permits unrestricted use, distribution, and reproduction in any medium, provided the original author and source are credited.

\begin{abstract}
Background

Rebound devices such as trampolines are associated with catastrophic spinal cord injuries. Cadaveric studies have reported thresholds for injuries that can be applied to the case of failed acrobatics such as backward somersaults. However, it remains unclear whether falls on rebound surfaces should be expected to cause neurological injuries in the majority of cases or only in unfortunate exceptions. The purpose of the current study is to demonstrate the risk of injury associated with a failed backflip performed on a rebound device such as a trampoline or tumbling trampoline.
\end{abstract}

\section{Methods}

Backward somersault kinematic data was acquired using subjects fitted with a safety harness. This data was then applied to a testing rig designed to set a Hybrid III Anthropometric Test Dummy (ATD) in rotation and released at precise timing so as to reproduce failed backward somersaults. The ATD was instrumented to measure rotational rate, head acceleration as well as stresses in the lower cervical region.

\section{Results}

The axial compression, shear force and flexion moment measured on average (SD) were respectively 1700 (470) $\mathrm{N}, 909(667) \mathrm{N}$, and 360 (122) Nm while the threshold for bilateral facet joint dislocation (BFD) shown by previous cadaver studies showed a significantly lower threshold $(p<0.001)$. Combined results have shown a likelihood of BFD for failed somersaults on tumbling trampolines ranging from 47 to $99 \%$.

\section{Conclusion}

Failed backward somersaults causing BFD are also likely to cause neurological damage. Therefore, use of rebound devices requires the need for progressive skill achievement; supervision for beginners and the use of additional safety measures must be emphasized to prevent inverted vertical falls resulting in the specific combination of forces necessary to cause BFD.

\section{Introduction}

Every year, thousands of people report to hospital emergency departments for trampoline related injuries [1-3]. Out of all these injuries, 8 to $12 \%$ are spinal injuries and of those injuries, approximately $5 \%$ result in permanent damage to the patient's neurological functions $[2,4]$.

Although many trampoline accidents involve accidental contact with the trampoline frame or excursions outside of the rebound surface, many of the spinal injuries which result in neurological damage occur within the parameters of regular trampoline use [5]. Multiple case studies of failed backward somersaults show the inadequacy of trampolines to protect the lower cervical spine from catastrophic injuries [6].

In order to understand the likelihood of such injuries and demonstrate the risk involved in the unsupervised use of such devices, a biomechanical study was carried out using a two-step approach. To accurately reproduce the conditions of such accidents, the kinematics of backward somersaults was acquired using beginner, intermediate, and expert gymnasts. The kinematic data was then applied to an 
Citation: Desmoulin GT, Marc Rabinoff, Brad Stolz, Michael Gilbert (2014) A Biomechanical Method for Reconstruction of Tumbling TrampolineAssociated Cervical Spine Injuries Using Human and Anthropometric Test Dummy Data. Forensic Biomechanics 5: 1000115. doi: $10.4172 / 2090-2697.1000115$

Page 2 of 6

Anthropometric Test Dummy (ATD) instrumented to measure cervical loads.

\section{Background}

The risk associated with trampolines and other rebound devices has long been known [6]. Reports of fractures and fracture-dislocations have become quite common [7]. However, serious neurological damage can occur at much lower stresses when dealing with Bilateral Facet Dislocations (BFD) $[3,8,9]$. The risk of dislocations can therefore be considered as a minimal threshold for possible catastrophic spinal injuries when looking at trampolines. The potential for spinal cord lesions and quadriplegia in the case of BFD has been reported to be between 50 to $84 \%[10,11]$.

Ivancic et al. [12] have shown such injuries to occur when the spinal cord is subject to a combination of loads as low as $264.5 \mathrm{~N}$ in compression, $54.5 \mathrm{~N}$ in shear and $17.7 \mathrm{Nm}$ in flexion for the C5/C6 spinal unit. The threshold of neighbouring spinal units was reported as being slightly higher in flexion moment as shown in Table 1, while other stress types were comparable.

\begin{tabular}{|l|l|l|l|}
\hline Loading & C3/C4 & C5/C6 & C7/T1 \\
\hline $\begin{array}{l}\text { Axial } \\
\text { Compression (N) }\end{array}$ & 215.5 & 264.5 & 226.7 \\
\hline Anterior Shear (N) & 60.6 & 54.5 & 108.3 \\
\hline $\begin{array}{l}\text { Flexion Moment } \\
(\mathrm{Nm})\end{array}$ & 35.3 & 17.7 & 37.4 \\
\hline
\end{tabular}

Table 1: Neck load tolerance values as reported by Ivancic et al. [12].

Nightingale et al. also observed this type of injury in cadaver head and neck rotationally constrained and under axial loadings [8]. It may be observed that this type of constraint is comparable to the behaviour of a head pushed into a compliant surface. The values obtained by this research group, however, differ from the Ivancic findings [12] by showing a more conservative injury threshold of $1720 \pm 1234 \mathrm{~N}$ (mean $\pm \mathrm{SD}$ ) for axial loads exclusively. A similar study by the same research group has also shown two dislocations caused by pure flexion moments with thresholds of $36.2 \mathrm{Nm}$ at $\mathrm{C} 1-\mathrm{C} 2$ and $42.2 \mathrm{Nm}$ at C2-C3 [13]. Although these results cannot be directly compared Ivancic's results on a spinal unit basis, the order of magnitude of these results is very similar to the most caudal spinal units reported by Ivancic [12].

The results published by the two research groups offer a range in which the BFD can be expected to occur. This can therefore be applied as injury threshold when interpreting the results of an analogous model.

Further, this type of injury occurs quickly according to Winkelstein and Myers' 1997 review paper [14]. By imaging the mechanism as it took place, cervical spine injuries have been shown to occur in less than $20 \mathrm{~ms}$.

\section{Materials and Methods}

\section{Human surrogate testing}

Backward somersault kinematic data was acquired by using 8 test subjects of varying skill level, height and weight whose informed consent was obtained. Table 2 summarizes the biometrics and skill level of each subject. The former was assessed by an expert in gymnastics [15].

\begin{tabular}{|l|l|l|l|}
\hline $\begin{array}{l}\text { Subject } \\
\text { ID* }\end{array}$ & $\begin{array}{l}\text { Weight } \\
(\mathrm{kg})\end{array}$ & $\begin{array}{l}\text { Height } \\
(\mathrm{cm})\end{array}$ & $\begin{array}{l}\text { Gender } \\
(\mathrm{M} / \mathrm{F})\end{array}$ \\
\hline B1 & 59.5 & 170.8 & $\mathrm{M}$ \\
\hline B2 & 69.7 & 175.3 & $\mathrm{M}$ \\
\hline B3 & 73.3 & 176.3 & $\mathrm{M}$ \\
\hline B4 & 64.0 & 185.9 & $\mathrm{M}$ \\
\hline B5 & 54.9 & 171.5 & $\mathrm{M}$ \\
\hline I1 & 77.7 & 182.6 & $\mathrm{M}$ \\
\hline E1 & 65.5 & 170.7 & $\mathrm{~F}$ \\
\hline E2 & 63.4 & 165.1 & $\mathrm{~F}$ \\
\hline E3 & 53.8 & 159.0 & $\mathrm{~F}$ \\
\hline
\end{tabular}

Table 2: Subject biometrics and gymnastics proficiency. ${ }^{*} \mathrm{~B}$ : Beginner I: Intermediate; E: Expert.

Subjects were instrumented using light-reflective markers as to track rotation of their torso and head (Figure 1).

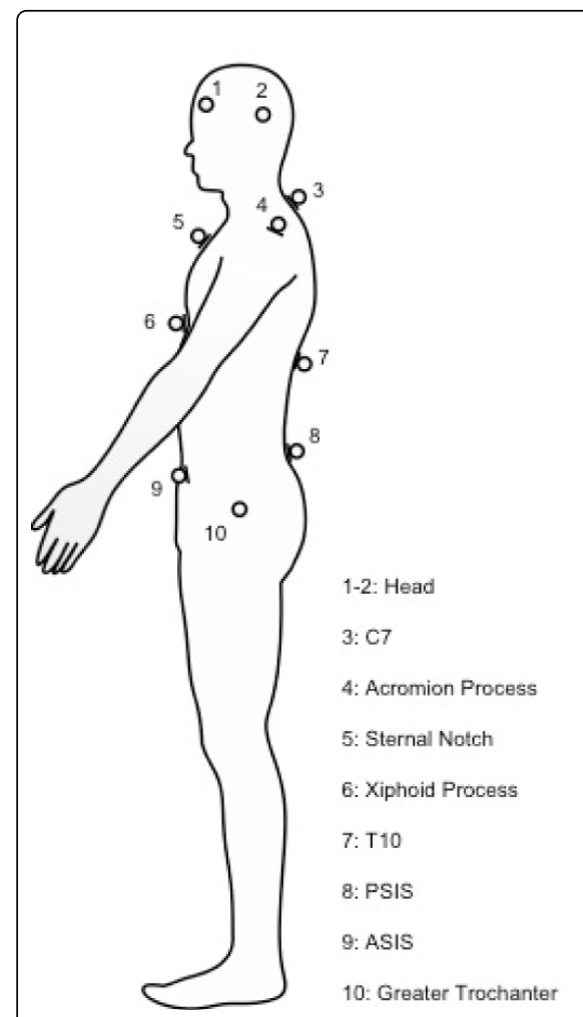

Figure 1: Marker placement (PSIS: Posterior Superior Iliac Spine and ASIS: Anterior Superior Iliac Spine).

For improved safety, the subjects were placed into a gymnastic harness, which was attached to an overhead traveling rig installed above the rebound device. The harness allowed freedom of movement 
Citation: Desmoulin GT, Marc Rabinoff, Brad Stolz, Michael Gilbert (2014) A Biomechanical Method for Reconstruction of Tumbling TrampolineAssociated Cervical Spine Injuries Using Human and Anthropometric Test Dummy Data. Forensic Biomechanics 5: 1000115.

Page 3 of 6

to jump and rotate while allowing a spotter to prevent accidental contact of the head or neck on the rebound surface.

Each subject was asked to perform at least 3 backward somersaults under each of the following conditions: using 2 preliminary bounces, using 1 preliminary bounce, using no preliminary bounce. All somersaults were recorded using a high-speed Photron Camera positioned laterally as to observe motion in the sagittal plane. The footage was then processed to extract the head and limb angles using the "Normal Angle" tool of Silicon Coach Software. The "Stop Watch" function was also used to identify the time at which the subject reached the "inverted position". This time was used as the "time of impact".

Head and limb angle were measured using the reflective markers at a sampling rate of $100 \mathrm{~Hz}$ as shown in Figure 2. Angular rate of change was measured and filtered using a 9-point moving average.

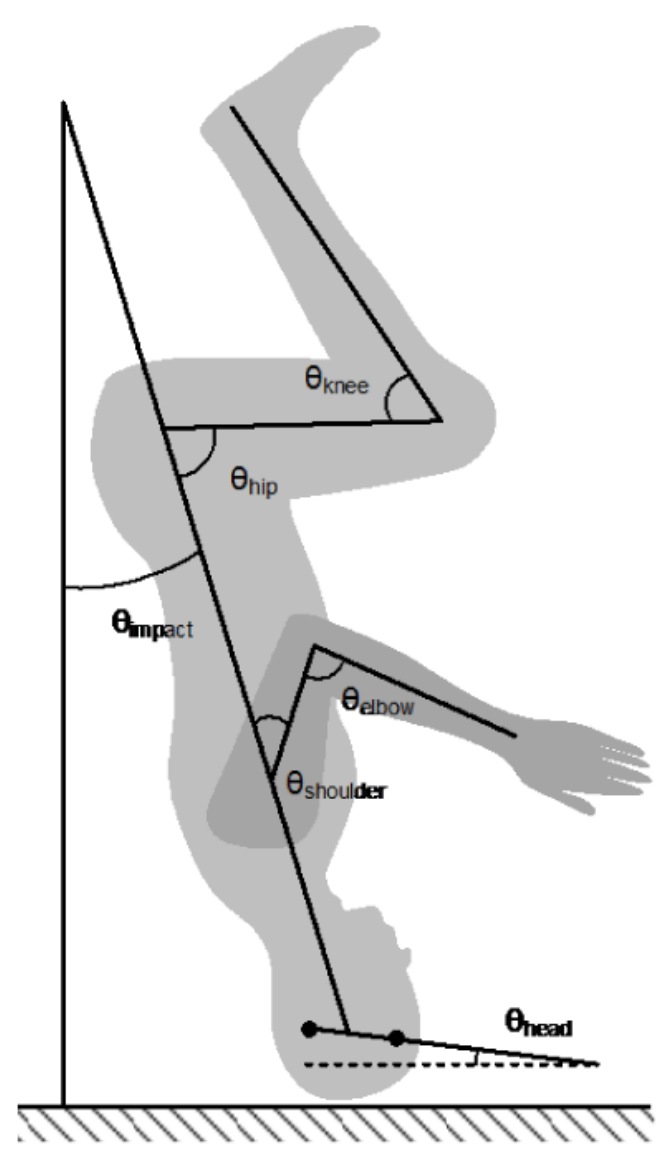

Figure 2: Angle measurement convention.

To measure jump height, one subject was instructed to perform vertical jumps in the same manner they would if they intended to perform a backward somersault. Jumps were performed using each of preliminary jump conditions previously described. The Stop Watch function was then used to measure the subject's air time, from toe off to toe on, and calculate the jump height based on the equation of motion of a free falling body strictly under the effects of gravity.
The rebound device used for this test was a tumbling trampoline (TT), $30 \mathrm{ft}$ in length and 6.9 feet in width.

\section{ATD Drop testing}

Using the kinematic data obtained through human surrogate testing, the conditions of a failed backward somersault injury were reproduced using a fifty percentile male Hybrid III anthropomorphic test dummy (Humanetics ATD, 78051-218-H, Huron, OH). To conservatively reconstruct falls suffered by beginners, as the lower beginner rotational rates were used with the lower jump heights recorded.

To effectively reproduce the kinematics of a full-scale failed backward somersault, a testing rig was designed and constructed in order to achieve repeatable, predictable testing results (Figure 3).

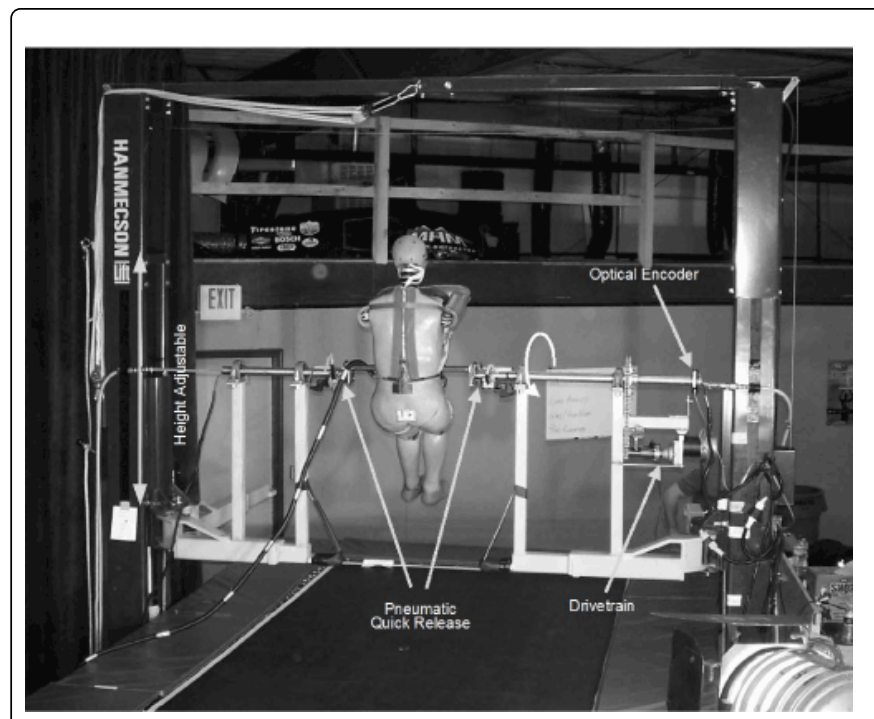

Figure 3: ATD testing rig.

This rig used an electric motor coupled to an optical encoder, with a closed-loop feedback control system. The encoder was mounted directly to the axle that held the dummy in order to achieve a desired rotational speed of the system. The ATD was mounted on a pneumatic quick-release axle coupled with the geared motor. A hydraulic lift was used to control the height of the axle from which the rotating dummy would drop. The system was controlled via software where the rotation speed could be programmed and monitored relative to the pneumatic quick-release of the dummy. During each test, the dummy was rotated to a prescribed angular rate and then released at a precise moment such that the dummy would rotate, fall, and contact the trampoline surface at a desired orientation.

An angular rate sensor (Diversified Technical Systems, ARS-1500, Seal Beach, CA) positioned in the posterior portion of the pelvic region was also used to measure the torso rate of rotation. A standard CFC180 filter was then applied to the signal [11]. The same laterally positioned camera setup was used to measure the head angle at impact and confirm the rotational rate measured by the angular rate sensor. Markers were positioned on the ATD, in a similar manner as with the human subjects as to extract head angle at impact and rotational rate.

To describe the loads applied to the cervical spine, a 6-axis load cell (Humanetics ATD, IF-210-HC, Huron, and $\mathrm{OH}$ ) was positioned at the 
Citation: Desmoulin GT, Marc Rabinoff, Brad Stolz, Michael Gilbert (2014) A Biomechanical Method for Reconstruction of Tumbling TrampolineAssociated Cervical Spine Injuries Using Human and Anthropometric Test Dummy Data. Forensic Biomechanics 5: 1000115. doi: 10.4172/2090-2697.1000115

Page 4 of 6

junction between the neck and thorax of the dummy. This junction can be assumed to represent the approximate location of the C5/C6 spinal unit. Acceleration of the head was measured by two sets of 3 linear accelerometers (Endevco, \#7264C-2K, Irvine, CA) positioned orthogonally at the head's center of gravity. Head Injury Criterion or HIC (HIC15 and HIC36) was then calculated for each dataset. All data collected by the load cell and accelerometers was filtered using a standard CFC1000 filter, in accordance with SAE J211.

The same laterally positioned camera setup was used to measure the head angle at impact and confirm the rotational rate measured by the sensor. Markers were positioned on the head of the ATD, in a similar manner as with test subjects.

Tests with ATD were carried out on the same tumbling trampoline as for human testing. For comparison purposes, the same ATD tests were repeated on a high performance trampoline ( $6 \mathrm{ft}$ by $12 \mathrm{ft}$ ). This trampoline was qualitatively observed as being more compliant than the TT.

Please describe here shortly the statistical evaluation.

\section{Results}

\section{Human surrogate testing}

The average jump heights were measured at $0.75,1.03$, and $1.09 \pm$ $0.01 \mathrm{~m}$ for standing, one and two bounces respectively. Limb orientations were also measured for each jump and averaged as shown in Table 3. The average was subsequently used for the ATD drop test.

\begin{tabular}{|l|l|l|}
\hline Joint & Avg Angle \pm SD (deg) & $\begin{array}{l}\text { Range } \\
\text { (deg) }\end{array}$ \\
\hline Elbow Angle $\Theta 1$ & $115 \pm 10$ & 45 to 180 \\
\hline Shoulder Angle $\Theta 2$ & $19 \pm 13$ & -41 to 178 \\
\hline Hip Angle $\Theta 3$ & $65 \pm 4$ & 21 to 83 \\
\hline Knee Angle $\Theta 4$ & $76 \pm 7$ & 39 to 127 \\
\hline
\end{tabular}

Table 3: Joint angles at impact, measured in the sagittal plane.

Rotational rates varied greatly amongst skill levels. However, expert gymnasts (E1, E2) showed higher rotational speeds than beginners and intermediate gymnasts with an average of $515 \pm 55 \mathrm{deg} / \mathrm{sec}$ with a range of 354 to $667 \mathrm{deg} / \mathrm{sec}$ as shown in Figure 4.

In comparison, the results of the more novice subjects (B1-B5, I1) averaged at $291 \pm 14 \mathrm{deg} / \mathrm{sec}$ with a range of 149 to $455 \mathrm{deg} / \mathrm{sec}$. An Independent Samples $t$-test performed on these results shows expert rotational rates as significantly higher compared to the less experienced gymnasts and, therefore, should not be used interchangeably $(p<0.0001)$. The rotational rate results of the beginners were therefore chosen as the range to use for ATD trials.

\section{ATD Drop testing}

A total of 44 trials were performed. The body angle at impact for these simulated failed backward somersaults averaged at $13.5 \pm 17.4$ deg with a range of -29 to $47 \mathrm{deg}$ with respect to the vertical.

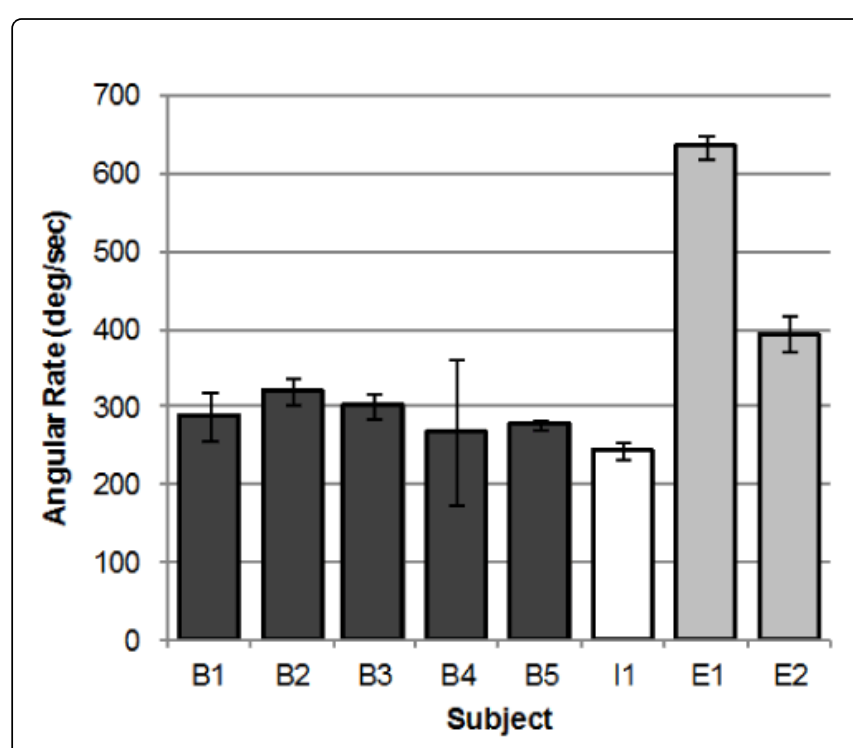

Figure 4: Average angular rate at impact grouped by skill level. Under a one-way t-test, the average of the data highlighted by horizontal line has been shown to be significantly greater $(\mathrm{p}<0.0001)$ when compared to the rest of the data.

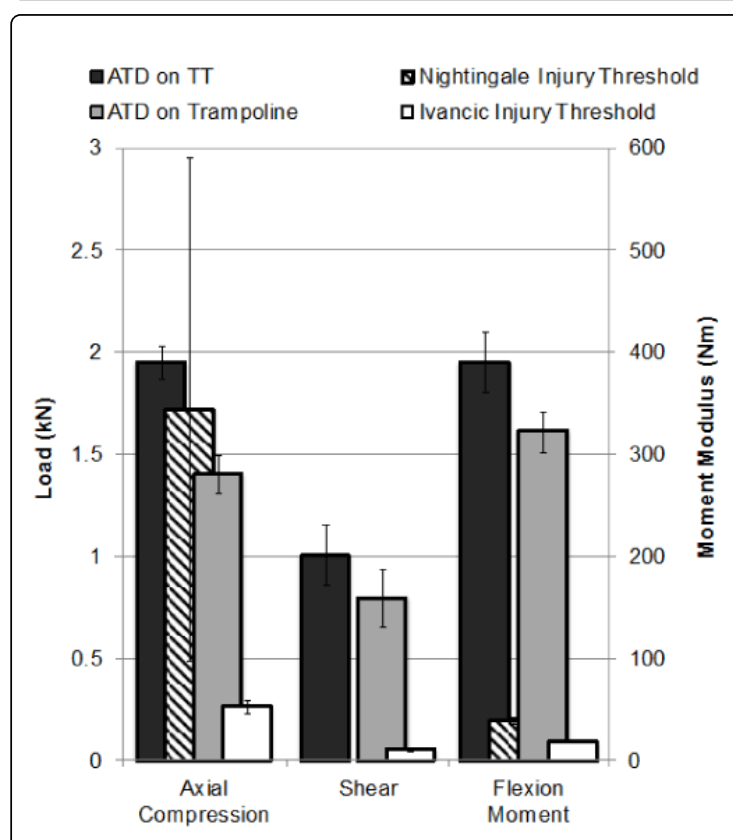

Figure 5: ATD maximal loads for each axis.

The measured loads are displayed in Figure 5 along with the C5/C6 bilateral facet dislocation tolerance values reported by Ivancic et al. [12] and Nightingale $[8,13]$.

The peak values collected during the current study can be seen breaching the Ivancic threshold on average $24.0 \pm 5.1 \mathrm{msec}$ and $23.0 \pm$ $4.8 \mathrm{msec}$ after impact for the TT and high performance Trampoline data, respectively. 
Citation: Desmoulin GT, Marc Rabinoff, Brad Stolz, Michael Gilbert (2014) A Biomechanical Method for Reconstruction of Tumbling TrampolineAssociated Cervical Spine Injuries Using Human and Anthropometric Test Dummy Data. Forensic Biomechanics 5: 1000115. doi: $10.4172 / 2090-2697.1000115$

Page 5 of 6

Figure 6 shows neck load data in relation with rotational rate. The data is largely concentrated between $200-300 \mathrm{deg} / \mathrm{sec}$. The relationship is non-linear but indicates higher loads for lower angular rates.

\section{Discussion}

The purpose of this study was to investigate the likelihood of cervical injury for failed backward somersaults on rebound devices such as trampolines and tumbling trampolines by using BFD as a benchmark for injuries.

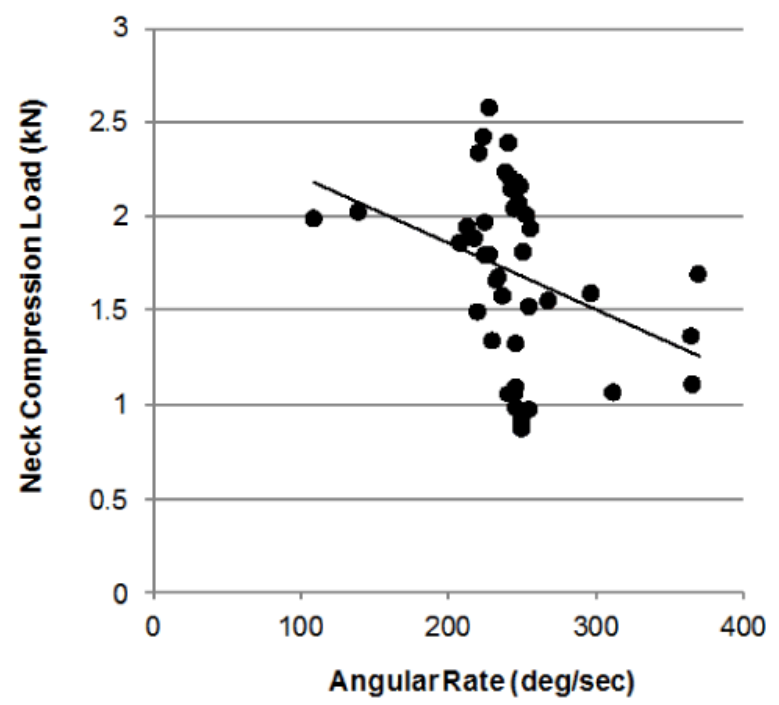

Figure 6: Neck compression load vs. angular rate at impact point.

The HIC values recorded for the entire study ranged from 3 to 32 . These values are well below the allowable limit of mid-sized males for automobile accidents which stands at 1000 [16].

The results collected collected on the TT show compression loads on average 7 fold higher (from 3.3 to 9.7) than the injury threshold of a C5/C6 spinal unit reported by Ivancic [12]. The results observed on the trampoline also breach the injury threshold but at lower values, which is expected considering the higher compliance of the trampoline over the TT. One may also wish to compare the values obtained with the Nightingale injury threshold of $1720 \mathrm{~N}$ for a rotationally constrained head $[8,13]$. In this instance, the results are more closely matched but still significantly different between the two devices with average stresses of $1949 \pm 79 \mathrm{~N}$ (TT) and $1401 \pm 90 \mathrm{~N}$ (Trampoline).

Statistically speaking, the likelihood of injury can be qualified using a cumulative probability plot based between the results and the injury thresholds. In the case of the Ivancic thresholds, the results show a 99.99\% probability of occurrence for breaching the threshold for all three measured stresses. Meanwhile, the Nightingale threshold shows a likelihood of injury of $47.01 \%$ based on its axial compression threshold. In other words, one may consider the likelihood of injury for a failed backward somersault on a rebound device to stand between $47 \%$ and $99.99 \%$.

According to the results shown by Ivancic, the threshold loads to cause disarticulation of the spine at C5-C6 are accompanied with a narrowing of the spinal canal. This canal pinch diameter has been measured post injury to be $2.2 \pm 0.8 \mathrm{~mm}$ in terms of average and standard deviation. This relatively small compression does not explain the spinal cord lesion that typically occurs [17]. What does explain the spinal cord lesion is the follow through loading or dynamic loading that continues to increase the canal pinch diameter roughly three times that of post impact narrowing [17] at $6.4 \pm 3.6 \mathrm{~mm}$. Figure 7 illustrates the increased pinch suffered by the spinal cord through the three key momentss of the injury.
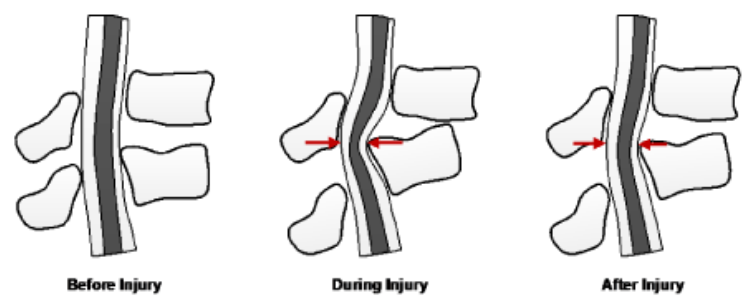

Figure 7: BFD damage to the spinal cord.

Moreover, the time required for all three of Ivancic's injury thresholds to be exceeded stands at 24 and $23 \mathrm{msec}$ on average for the TT and Trampoline respectively. This is in close agreement with the cited articles $[14,18]$ since the current experiments were performed on a more compliant surface that would tend to increase the time to peak load.

Further, cervical spinal cord injuries often result from the incapacity of the neck to stop the mass of the moving torso. Experiments show that neck injuries can be produced with only a percentage of torso weight, approximately $16 \mathrm{~kg}$, following the head and neck in an impact with a velocity of $3.1 \mathrm{~m} / \mathrm{s}$ which corresponds to a drop height of about $0.5 \mathrm{~m}$ which is lower than the minimal value drop test of $0.66 \mathrm{~m}$ used in the current study $[9,18]$.

The type of surface also has an effect on neck injury [19]. In some head impacts, the head and neck are able to bend out of the path of the momentum of the torso that follows; the torso (chest, shoulders, or back) then contacts the surface and absorbs the torso momentum without loading the neck. This sort of behaviour is made less likely when dealing with rebounding devices such as a TT or a trampoline because of the reaction of the surface to the contact. As previously explained by Winklestein and Myers the pocketing of the head by a compliant impact surface reduces the ability of the head and neck to move out of the way of the torso and can increase the risk for neck injury [14]. This behaviour of the contact surface can be observed in the high speed videos of the simulated ATD falls as shown in Figure 8 which illustrate this point on a TT.

Additionally, the relationship seen between neck load and angular rate further confirms that a beginner performing a backward somersault at a lower angular rate would be more susceptible to suffer from the pocketing effect. To understand this, one may consider the opposite case where, at higher rotational velocities, the additional momentum of the body would tend to reduce the duration at which the inertia of the torso is aligned with the spine thus limiting the pocketing effect. 
Citation: Desmoulin GT, Marc Rabinoff, Brad Stolz, Michael Gilbert (2014) A Biomechanical Method for Reconstruction of Tumbling TrampolineAssociated Cervical Spine Injuries Using Human and Anthropometric Test Dummy Data. Forensic Biomechanics 5: 1000115. doi: $10.4172 / 2090-2697.1000115$

Page 6 of 6

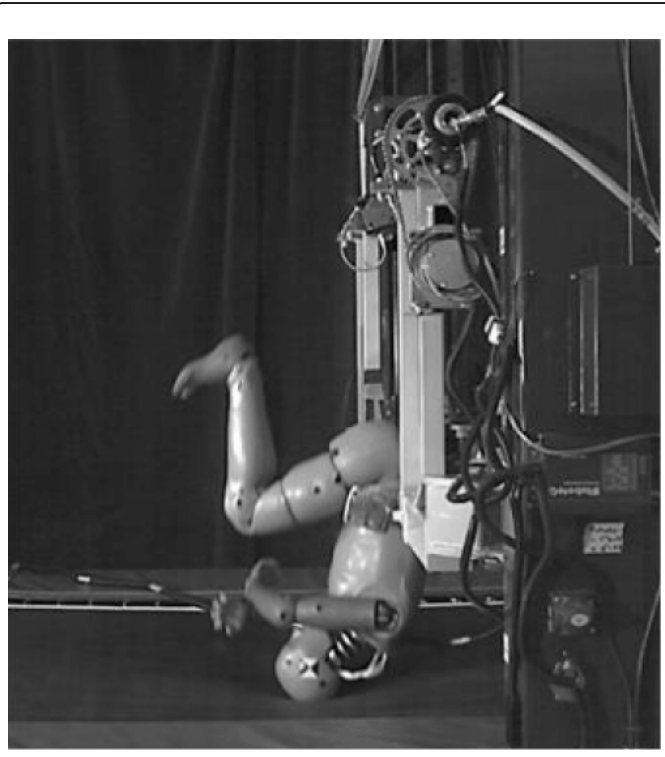

Figure 8: Head pocketing as reproduced during ATD testing.

In summary, five published mechanisms of injury agree with the test data: 1) Neck loads were sufficient to exceed reported thresholds to cause bilateral facet joint dislocation of $\mathrm{C} 3 / \mathrm{C} 4, \mathrm{C} 5 / \mathrm{C} 6$ or $\mathrm{C} 7 / \mathrm{T} 1$ which caused significant canal pinch diameter; 2) Time to reach these threshold levels correspond well with the literature for the given conditions; 3) Minimal drop heights determined by human surrogate tests exceed reported drop heights that can cause cervical neck injury; 4) With this lower drop height, only a fraction of body weight was required to cause neck injury; 5) "Pocketing" of the impact surface such as that of rebound devices such as trampolines and TT increases risk of neck injury.

\section{Conclusion}

With a likelihood of injury spanning from 47 to $100 \%$, vertical falls on trampolines and tumbling trampolines where the head is the primary point of contact represent an undeniable risk. The need for progressive skill achievement, supervision for beginners and the use of additional safety measures must be emphasized. Such measures are readily available in the form of spotting rigs and harnesses such as the ones used to acquire human kinematic data in the current study. With the help of a qualified coach and spotter the risk of head contact caused by a failure to complete a somersault manoeuver is practically eliminated, thus eliminating the potential for injury.

\section{Acknowledgment}

The authors would like to thank the attorneys at Eisenberg Rothweiler Winkler Eisenberg \& Jeck P.C. for funding this important research in connection with the litigation captioned Duchesneau v. TumblTrak and Cornell University, and for providing the authors with unfettered discretion in designing their methodology, conducting their investigation, and reaching their conclusions. Furthermore, the authors extend their gratitude to Mr. John Martin, KARCO Engineering LLC., Mr. Kody Sale, Ms. Christina M. Stevens and Mr. Mark Nolette.

\section{Funding}

The funding for this research originated from the firm Eisenberg Rothweiler Winkler Eisenberg \& Jeck P.C. in the context of the litigation captioned Duchesneau v. TumblTrak and Cornell University.

\section{Nomenclature}

ATD: Anthropometric Testing Dummy

BFD: Bilateral Facet Dislocation.

\section{References}

1. Brown PG, Lee M (2000) Trampoline injuries of the cervical spine. Pediatr Neurosurg 32: 170-175.

2. Furnival RA, Street KA, Schunk JE (1999) Too many pediatric trampoline injuries Pediatrics.

3. Bauze RJ, Ardran GM (1978) Experimental production of forward dislocation in the human cervical spine. J Bone Joint Surg Br 60: 239-245.

4. Silver J, Silver D, Godfrey JJ (1986) Trampolining injuries of the spine. Injury, 17: 117-124.

5. Nysted M, Drogset JO (2006) Trampoline injuries. British journal of sports medicine 40: 984-987.

6. Ellis WG, Green D, Holzaepfel NR, Sahs A (1960) The Trampoline and Serious Neurological Injuries: A Report of Five Cases JAMA: The Journal of the American Medical Association 174: 1673-1676.

7. Torg JS, Das M (1984) Trampoline-related quadriplegia: review of the literature and reflections on the American Academy of Pediatrics' position statement. Pediatrics 74: 804-812.

8. Nightingale WR, Doherty JB, Myers SB, McElhaney H J, Richardson, et al. (1991) The influence of end condition on human cervical spine injury mechanisms, Society of Automotive Engineers, New York, NY, United States.

9. Nightingale RW, McElhaney JH, Richardson WJ, Best TM, Myers BS (1996) Experimental impact injury to the cervical spine: relating motion of the head and the mechanism of injury. J Bone Joint Surg Am 78: 412-421.

10. Wolf A, Levi L, Mirvis S, Ragheb J, Huhn S, et al. (1991) Operative management of bilateral facet dislocation. Journal of neurosurgery 75 : 883-890.

11. O'Brien PJ, Schweigel JF, Thompson W (1982) Dislocations of the lower cervical spine. J Trauma acute care surgery 22: 710-714.

12. Ivancic PC, Pearson AM, Tominaga Y, Simpson AK, Yue JJ, et al. (2008) Biomechanics of cervical facet dislocation. Traffic Inj Prev 9: 606-611.

13. Nightingale RW, Carol Chancey V, Ottaviano D, Luck JF, Tran L, et al. (2007) Flexion and extension structural properties and strengths for male cervical spine segments. J biomech 40: 535-542.

14. Winkelstein BA, Myers B S (1997) The biomechanics of cervical spine injury and implications for injury prevention. Med Sci Sports Exerc, 29: 246-255.

15. Kilbride J (2007) Case Murray v Chicago Youth Center. Supreme Court of the State of Illinois.

16. Nahum AM, Melvin J (2002) Accidental injury: biomechanics and prevention, Springer.

17. Ivancic P, Pearson A, Tominaga Y, Simpson A, Yue J, et al. (2007) Mechanism of Cervical Spinal Cord Injury During Bilateral Facet Dislocation. Spine 32: 2467-2473.

18. Nightingale RW, McElhaney JH, Richardson WJ, Myers BS (1996) Dynamic responses of the head and cervical spine to axial impact loading. J Biomech 29: 307-318.

19. Swartz EE, Floyd R, Cendoma M (2005) Cervical spine functional anatomy and the biomechanics of injury due to compressive loading. Journal of athletic training 40: 155-161. 